\title{
USING OF COCONUT MILK IN THE PRODUCTION OF ICE MILK
}

\author{
1*Abdalrahman Nabeel Abdalrazaq AL-Hyali, ${ }^{2}$ Ghanem Mahmoud Hassan \\ ${ }^{1 *, 2}$ Department of Food Science, College of Agriculture and Foresty, University of Mosul, Mosul, Iraq \\ E-mail: ${ }^{1 *}$ Abdalrhman.alhealy.2020@gmail.com, ${ }^{2}$ dralabbasi58@yahoo.com
}

(Received March 26, 2021; Accepted May 12, 2021; Available online September 01, 2021)

DOI: 10.33899/edusj.2021.129793.1149, (C) 2021, College of Education for Pure Science, University of Mosul.

This is an open access article under the CC BY 4.0 license (http://creativecommons.org/licenses/by/4.0/).

\begin{abstract}
This study was conducted for the purpose of making milk ice cream free from lactose and to demonstrate the effect of replacing cows' milk with coconut milk on the general characteristics of the product, as it was observed in samples made from coconut milk a high percentage of total solids, a slight increase in the percentage of fat and a decrease in the percentage of total sugars. While the percentage of protein and ash increased, so did the $\mathrm{pH}$ value of the mixture, and the percentage of the restorative acidity of the product decreased, and The specific weight of the mixture and the product decreased, the relative viscosity increased, the percentage of rent increased, the percentage of shrinkage increased, the product's resistance to melting increased, the caloric content of the product increased, and the degrees of sensory evaluation increased with the increase in the substitution ratios with coconut milk, and the total number of bacteria, coliform and Staph bacteria increased. aureus in coconut milk samples.
\end{abstract}

keywords: Plant milk, Coconut, Ice cream, Over run, Deflation.

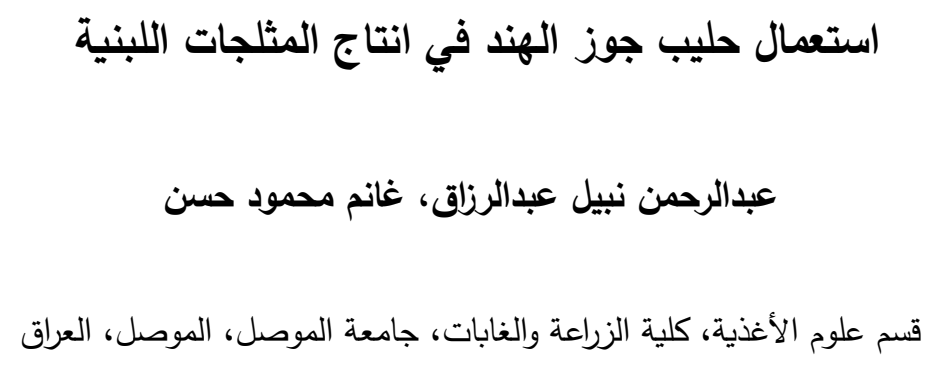

الخلاصة

أجريت هذه الدراسة لغرض تصنيع مثلجات لبنية ذات محتوى قليل من سكر اللاكتوز وبيان تأثير استبدال حليب الابقار

بحليب جوز الهند على الصفات العامة للمنتوج، واستخدمت طريقة الاستخلاص بإضافة حليب الفرز ، احتوى حليب جوز الهند الناتج على نسبة اعلى من الدهن والمواد الصلبة اللادهنية ونسبة اعلى من البروتين بالمقارنة مع حليب الابقار، واستبدل حليب الابقار الطازج بحليب جوز الهند بنسب استبدال (35\% ، 70\% ، 100\%) ولوحظ في العينات المصنعة من حليب جوز الهند ارتفاع نسبة المواد الصلبة الكلية وارتفاع طفيف في النسبة المئوية للدهن بسبب موازنة نسبة الدهن في المخلوط باستخدام القشدة وانخفاض

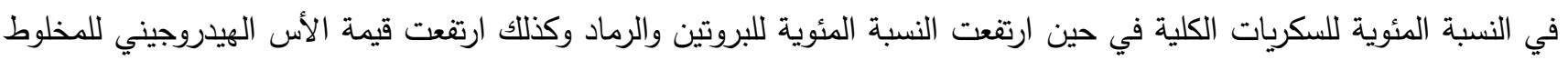




\section{Journal of Education and Science (ISSN 1812-125X), Vol: 30, No: 4, 2021 (83-93)}

وانخفضت النسبة المئوية للحموضة التسحيحية للمنتج وانخفض الوزن النوعي للمخلوط والمنتج وارتفعت اللزوجة النسبية وكذلك ارتفعت النسبة المئوية للريع وازدادت النسبة المئوية للانكماش وازدادت مقاومة المنتج للانصهار وارتفعت السعرات الحرارية للمنتج وازدادت درجات التقييم الحسي مع زيادة نسب الاستبدال بحليب جوز الهند حتى بعد الخزن لمدة اسبوعين وازداد العدد الكلي للبكتريا وبكتريا القولون وبكتريا Staph. aureus في عينات حليب جوز الهند.

الكلمات المفتاحية: الحليب النباتي، جوز الهند، مثلجات لبنية، الريع، الانكماش.

\section{Introduction المقدمة}

المثلجات اللبنية هي منتوج لبني غذائي مبرد يحصل عليه نتيجة لتحريك وتجميد مخلوط مبستر معروف الخواص والتركيب. ويتكون الخليط اساساً من الحليب وبعض منتجاته والسكر أو أحد مشتقاته والماء مـع إضافة المطعمات والملونات أو من دونها وكذللك المستحلبات كالبيض أو بعض مكوناته بالإضافة إلى المواد الغذائية التي يمكن إضافتها [1].

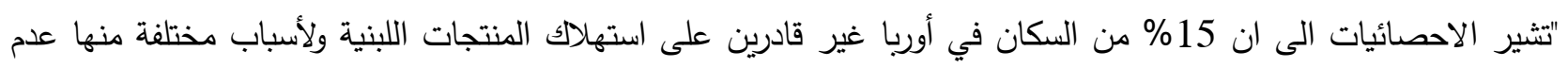

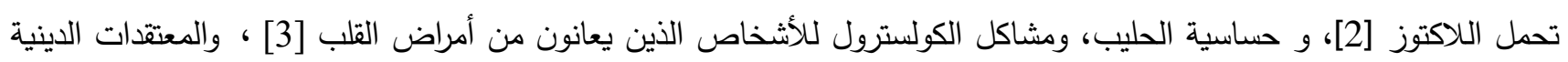

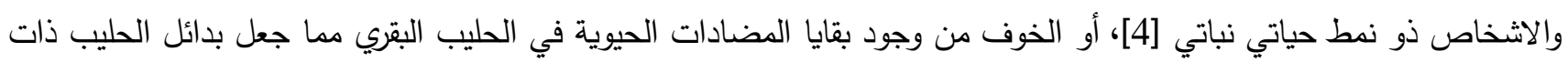
المصادر النباتية أكثر ملائمة لهذه الفئة." "وفي الوقت الحاضر فأنّ قطاع بدائل الحليب بدأ ينمو وبشكل كبير عالمياً، ولا تستهلك هذه البدائل عند العطش فقط، لأن

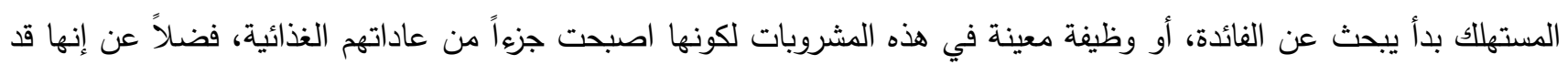
تلبي الاحتياجات اليومية كمصدر للطاقة ومكافحة الشيخوخة والتعب والتوتر أو تقلل من خطر الاصدابة بأمراض معينة [3]."

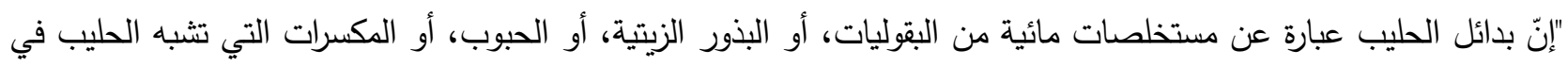

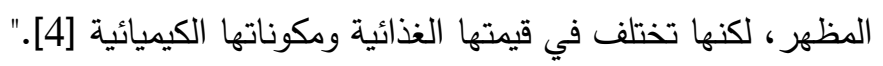
تضاف الى بدائل الحليب العديد من المركبات من اجل التدعيم لتحسين الطعم و القيمة الغذائية و القوام مثل الفيتامينات والمعادن والمحليات والنكهات والاملاح والزيوت والمثبتات [5] وبدائل الحليب التجارية في الغالب اما مبسترة أو معرضة الى لى حرارة عالية و6] (6HT) Ultra-high temperature.

\section{Materials and Methods المواد وطرائق العمل}

استخدم حليب الابقار الخام من الأسواق المحلية لمدينة الموصل وتم إجراء عملية التصفية وسخن الحليب إلى درجة 45-

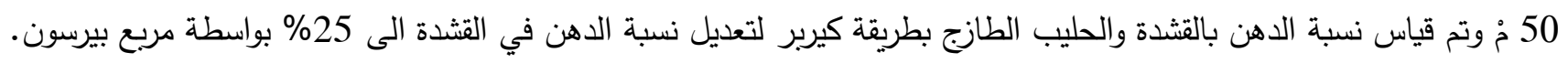

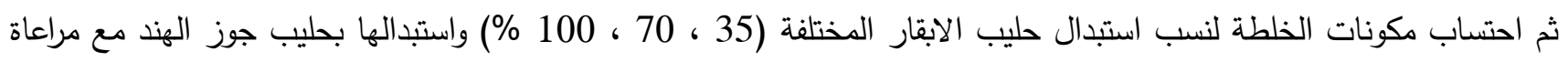
تثبيت النسبة المئوية للدهن والنسبة المئوية للمواد الصلبة اللادهنية وباستخدام المعادلات الرياضية الخاصة والموضحة من قبل

.[1] Salim

• • حضر حليب جوز وفقاً لما ذكره Kate [7]. 1- تم تسخين جوز الهند المبروش مع حليب الفرز وبنسبة 3:1 جوز هند : حليب فرز (وزن/حجم) على درجة حرارة 60 مْ لـدة 5 دقائق مع التحريك المستمر . 2- تم تصفية جوز الهند بوساطة قطعة مزدوجة من قماش الململ. 
3- بسترة حليب جوز الهند الناتج على درجة حرارة 85 مُ لمدة 5 دقائق، وبرد وحفظ في الثلاجة بدرجة حرارة (5 م ) بعبوات محكمة الغلق، لإجراء الفحوصات والمعاملات اللاحقة.

سخن الحليب الى درجة 45-50 مُ واضيفت المواد اليه كمية السكر المقدرة بـ 14\% بعد خلطها مع كمية المثبت وجميع المواد الجافة مع الخلط الجيد وتضاف بصورة تدريجية لتمام الذوبان واستمرار التحريك والتسخين حتى الوصول الى درجة حرارة 83 مْ ولمدة 15 ثانية، ومن ثم التبريد والتعتيق في الثلاجة عند 5 مْ ــ 2 مُ لمدة 4 ساعات ثم التجميد الاولي باستخدام جهاز التجميد

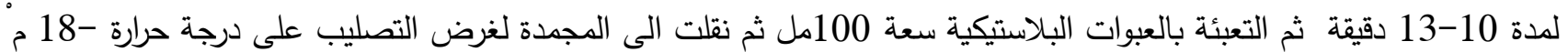
لحين التقويم واجراء التقديرات، التي تكون عادة بعد 24-48 ساعة. جدول (1) أوزان المكونات الداخلة في تصنيع 1 كفم خلطة مثلجات لبنية مستبدل بها حليب الابقار والقثدة بحليب جوز الهند.

\begin{tabular}{|c|c|c|c|c|}
\hline \multicolumn{4}{|c|}{ النسبة المئوية للاستبدال } & \multirow[t]{2}{*}{ المكونات (غم) } \\
\hline 100 & 70 & 35 & صفز & \\
\hline 63 & 91 & 123 & 156 & قثندة 25\% دهن \\
\hline - & 193 & 419 & 644 & حليب بقري طازج \\
\hline 737 & 516 & 258 & - & حليب جوز الهند \\
\hline 55 & 55 & 55 & 55 & حليب فرز مجف \\
\hline 140 & 140 & 140 & 140 & سكر \\
\hline 5 & 5 & 5 & 5 & مثبت \\
\hline 1000 & 1000 & 1000 & 1000 & المجموع \\
\hline
\end{tabular}

جدول (2أ) التركيب العام لأنواع المثلجات المنتجة في العرلق

\begin{tabular}{|c|c|c|c|c|c|c|}
\hline كحامض ستريك & \% أدنى & \% الكليةحد أدنى الصلبة & وز حدأدنى \% للسكرياتسكر & \% للادوادالصلبة & \% \%لا هنحد أدني & نوع المنتج \\
\hline--- & 100 & $38-33$ & 11 & 12 & 8 & والثبيهة بالمثلجات القثاتية \\
\hline--- & 75 & $32-28$ & 12 & 11 & 3 & المثلجات اللبنية \\
\hline 0.35 & 50 & $28-24$ & 20 & 3 & 1 & الشرابت المثلجة \\
\hline 0.35 & 20 & $24-21$ & 20 & صغر & صفر & المثلج \\
\hline
\end{tabular}

جدول (2ب) التركيب العام لأنواع المثلجات المنتجة في العراق

\begin{tabular}{|c|c|c|c|c|c|c|c|c|c|c|c|c|c|c|c|c|}
\hline \multicolumn{2}{|c|}{6} & \multicolumn{3}{|c|}{5} & \multicolumn{3}{|c|}{4} & \multicolumn{3}{|c|}{3} & \multicolumn{2}{|c|}{2} & \multicolumn{3}{|c|}{1} & \multirow{2}{*}{ المجاميع الفرعية الرئيسية } \\
\hline 2 & 1 & 3 & 2 & 1 & 3 & 2 & 1 & 3 & 2 & 1 & 2 & 1 & 3 & 2 & 1 & \\
\hline \multicolumn{2}{|c|}{ لا حليب ولا } & \multicolumn{3}{|c|}{ دهن حليب قليل و/او } & \multicolumn{3}{|c|}{ دهن الحليب و/او } & \multicolumn{3}{|c|}{ دن الحليب و/او اي } & \multicolumn{2}{|c|}{ دهن وبروتين } & \multicolumn{3}{|c|}{ دهن وبروتين } & لدهن، بروتين \\
\hline
\end{tabular}




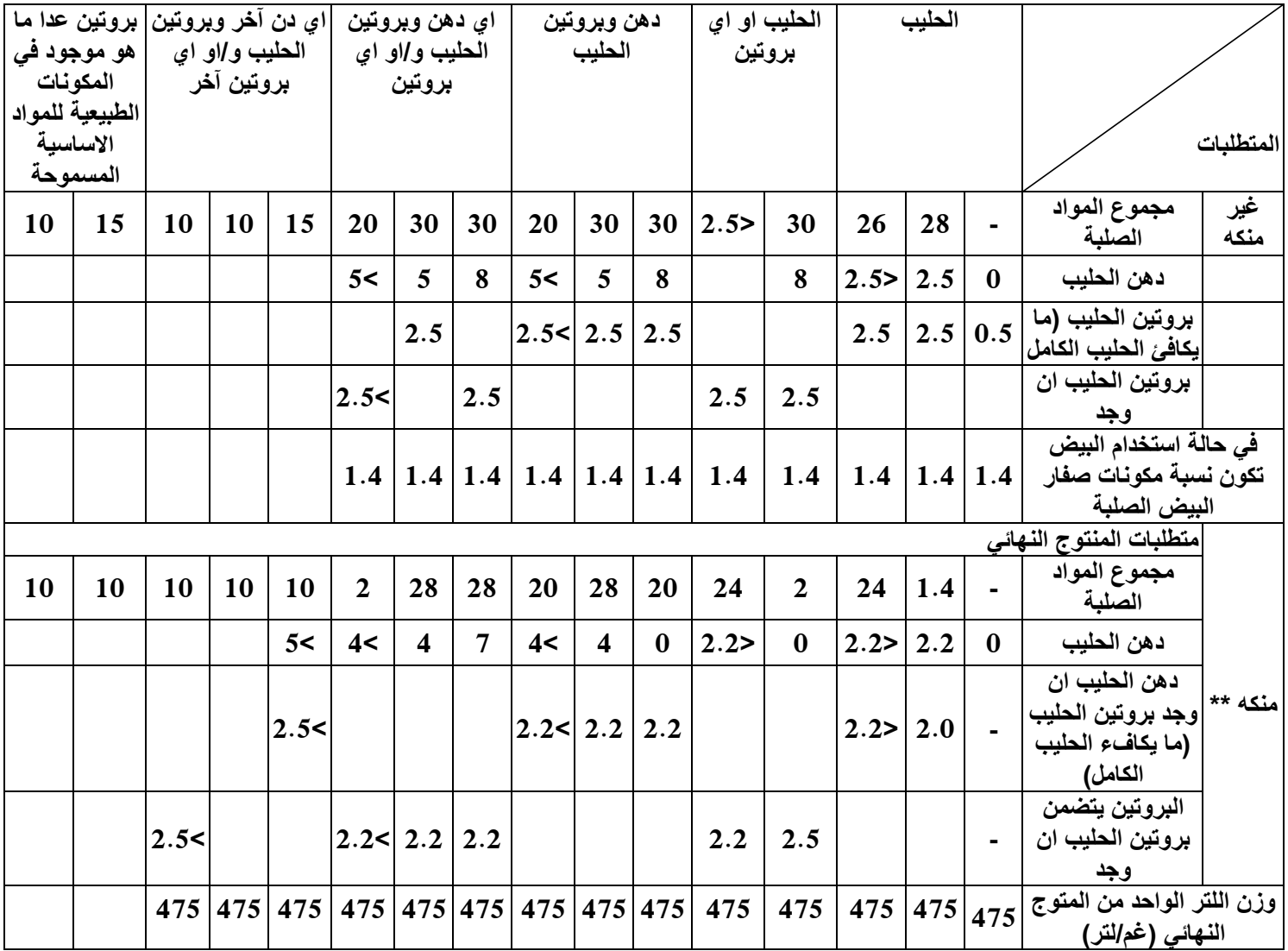

" يجوز احتواء كل واحد من المجاميع الاساسية مكونات اخرى والمسموح بها في (2-4-4) الى (3-4-8) والمضفات الغذائية المسموحة في (4) * * عند ذكر اسم نكهة معينة مع اسم المنتوج يراعى ان تكون مطابقة لطرق التصنيع الجديدة

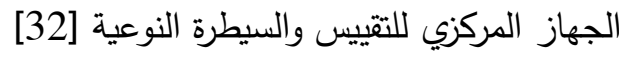

\section{التحاليل الكيميائية والتقديرات الفيزيائية}

تم تقدير المواد الصلبة الكلية والدهن حسب طريقة Min و Ellefson [8]، وقدرت قيمة الأس الهيدروجيني والبروتين والحموضة التسحيحية للمنتج حسب طريقة Hool [9] وقدرت الرطوبة بطريقة Bradley [10] وقدرت السكريات الكلية وفق ما ذكر Pearson [11] وقدر الرماد وفق طريقة Marshall [12] وقدر الوزن النوعي على وفق الطريقة المذكورة في Ling [13] وقدرت اللزوجة النسبية في المخاليط كما ذكرها Arbuckle [14] وحسب الريع للمنتج على وفق ما أشار إليه Salim [1] وقدر الانكماش وفيه ذكره

Al-Saeli الموصوفة من قبل Al-Zuhairi [17] وقيمت معاملات المنتج من قبل عدد من المتخصصين في قسم علوم الأغذية والتقانات

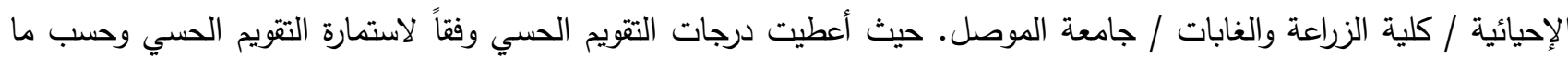

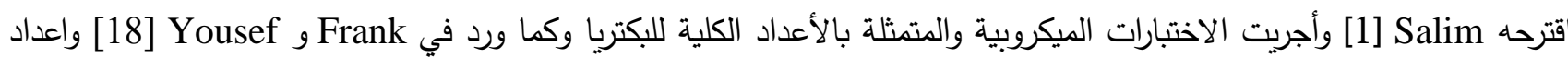
بكتريا القولون وفق ما ذكر Chen [19] وكما ورد في APHA و .[20] public Heallh - Association

\section{التحليل الإحصائي}

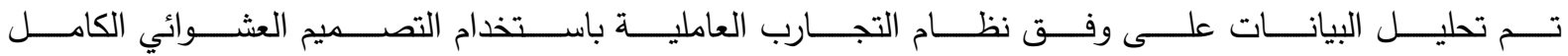
Factorial Experiment Conducted in C.R.D 
دنكن المتعـد المـدى تحت مسـتوى احتمـال 0.05 حيث استعمل برنـامج SAS (2001) باستخدام الحاسـوب لإجـراء التحليل الإحصائي للبيانات.

\section{Result and Discussion النتائج والمناقشة}

التحاليل الكيميائية

يبين الجدول (3) تركيب حليب جوز الهند بالمقارنة مع حليب الابقار إذ يلاحظ ارتفاع الآس الهيدروجيني لحليب جوز الهند وانخفضت النسبة المئوية للحموضة التسحيحية لحليب جوز الهند ويلاحظ من نفس الجدول انخفاض في النسبة المئوية للرطوبة في جوز الهند بسبب ارتفاع محتواه من الدهن والمواد الصلبة اللادهنية ويلاحظ من الجدول ايضاً ارتفاع النسبة المئوية

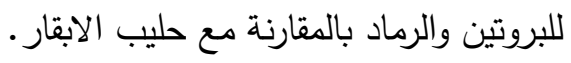

جدول (3) الفرق في التركيب الكيميائي بين حليب الابقار وحليب جوز الهند.

\begin{tabular}{|c|c|c|}
\hline حليب جوز الهند & حليب الابقار & الصفات المدروسة \\
\hline 6.69 & 6.65 & الأس الهيدروجيني \\
\hline 0.15 & 0.16 & النسبة المئوية للحموضة التسحيحية \\
\hline 84.96 & 88.61 & النسبة المئوية للرطوبة \\
\hline 9.03 & 8.10 & النسبة المئوية للمواد الصلبة اللادهنية \\
\hline 6.01 & 3.29 & النسبة المئوية للدهن \\
\hline 3.12 & 2.95 & النسبة المئوية لبروتين \\
\hline 0.91 & 0.75 & النسبة المئوية للرماد \\
\hline
\end{tabular}

ويبين الجدول (4) التركيب الكيميائي لمخاليط المثلجات اللبنية المستبدل فيها حليب الابقار بحليب جوز الهند وبنسب الاستبدال (35 ، 70 ، 100 \%) إذ يلاحظ من الجدول وجود فروق معنوية في المواد الصلبة الكلية بين نسب الاستبدال بالمقارنة

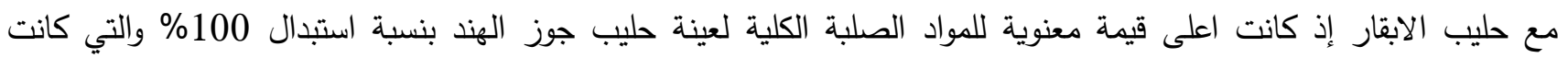
29.87\% في حين كانت اقل قيمة معنوية لعينة المقارنة والتي كانت 29.07\% ويعود السبب في ارتفاع في نسبة المواد الصلبة الى ارتفاع محتوى حليب جوز الهند من المواد الصلبة اللادهنية وكما هو موضح في الجدول (3) واتفقت النتائج مع ما وجده

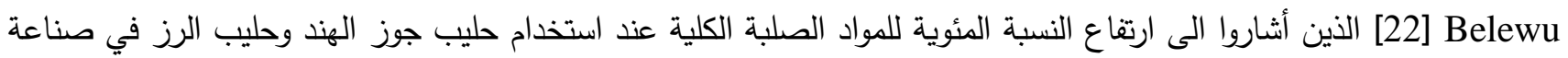
اللبن Yoghurt.

ويلاحظ من الجدول (4) ارتفاع طفيف في النسبة المئوية للدهن مع زيادة نسب الاستبدال ويعود ذلك لموازنة نسب الدهن في المخاليط بتحديد كمية القشطة المضافة وتتفق هذه النتائج مع ما وجده Balogun [23] والذي أشار الى ارتفاع نسبة الدهن عند استخدام حليب جوز الهند في صناعة جبن الـ Warankashi بدلاً من حليب الابقار . ويلاحظ من الجدول (4) انخفاض في النسبة المئوية للسكريات الكلية مع زيادة نسب الاستبدال بحليب جوز الهند الذئ إذ كانت

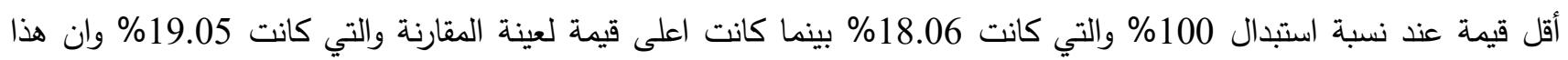
الانخفاض اتفق مع ما وجده Balogun [23] عند استخدام حليب جوز الهند في صناعة جبن الـ Warankashi. ويلاحظ من الجدول (4) ارتفاع في النسبة المئوية للبروتين مع زيادة نسب الاستبدال بحليب جوز الهند إذ كانت أعلى قيمة

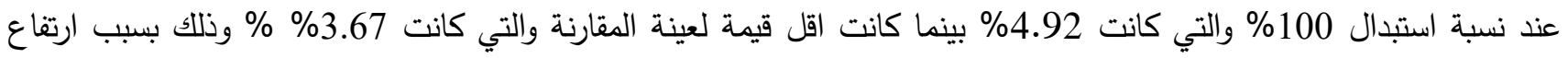


النسبة المئوية للبروتين في حليب جوز الهند والتي كانت 3.12\% كما موضح في الجدول (3) واتفقت هذه النتائج مع Akoma

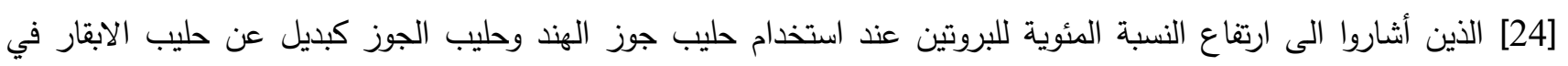
صناعة اليوكرت Yoghurt.

ويلاحظ من الجدول (4) ارتفاع في النسبة المئوية للرماد مع زيادة نسب الاستبدال بحليب جوز الهند إذ كانت أعلى قيمة

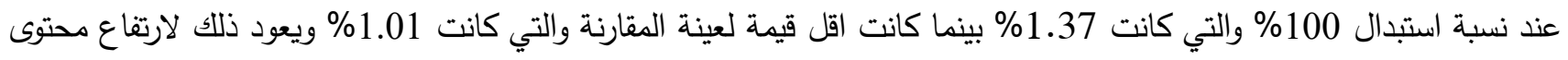
حليب جوز الهند من المواد الصلبة الكلية واتفتت هذه النتائج مع Okorie و Adedokun [25] اللذان أثنارا الى ارتفاع النسبة

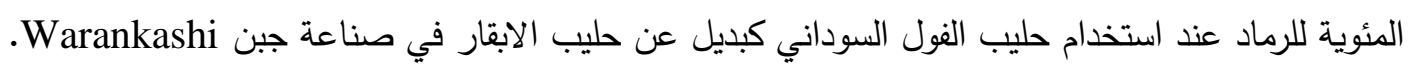

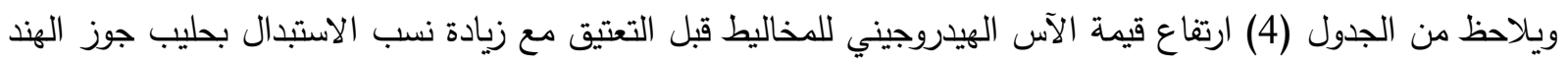
إذ كانت أعلى قيمة عند نسبة استبدال 100\% والتي كانت 6.71 بينما كانت اقل قيمة لعينة المقارنة والتي كانت 6.43 وقد يرجع السبب الى ارتفاع نسبة البروتين بزيادة نسب الاستبدال وقد يرجع السبب ايضاً الى ارتفاع قيمة الأس الهيدروجيني في حليب جوز

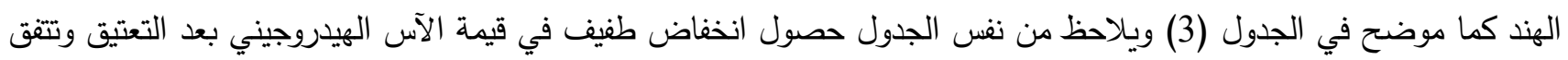

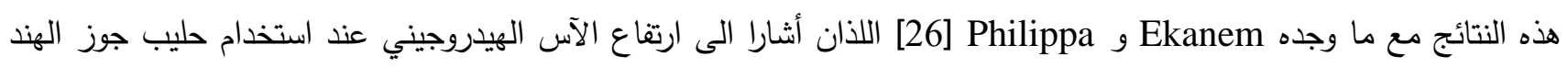

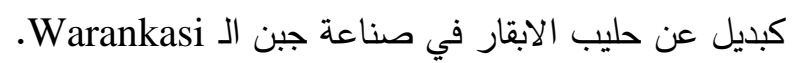
ويلاحظ من الجدول (4) انخفاض في النسبة المئوية للحموضة التسحيحية لمنتج المثلجات اللبنية مع زيادة نسب الاستبدال إذ كانت اعلى قيمة لعينة المقارنة والتي كانت 0.23\% بينما كانت اقل قيمة عند نسبة استبدال 100\% والتي كانت

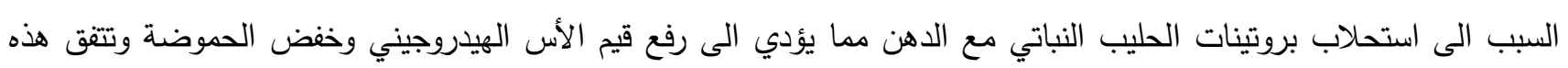
النتائج مع ما وجده Abdel-Rahman [27 الذي أثار الى حدوث انخفاض في النسبة المئوية للحموضة التسحيحية لمخلوط المثلجات اللبنية الحاوي على بروتينات فول الصويا المركز والذي أدى الى ارتفاع في قيمة الأس الهيدروجيني.

جدول (4) التركيب الكيميائي للمثلجات اللبنية المستبال فيها حليب الابقار بالحليب النباتي.

\begin{tabular}{|c|c|c|c|c|}
\hline \multicolumn{4}{|c|}{ النسبة المئوية للاستبدال } & \multirow{2}{*}{ المكونات } \\
\hline$\% 100$ & $\% 70$ & $\% 35$ & عينة المقارنة & \\
\hline 29.87 & 29.64 ب & 29.33 ج & 29.07 د & المواد الصلبة الكلية \\
\hline 5.52 & 5.47 & 5 5.39 ب & 5 5.34 ب & الدهن الد \\
\hline 18.06 د & 18.33 ج & 18.65 & 19.05 & السكريات الكلية \\
\hline 4.92 & ا & 4.11 ج & 3.67 د & البروتين \\
\hline 1.37 & 1.25 ب ب & ( & 1.01 & 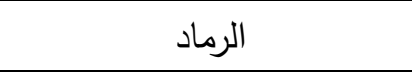 \\
\hline 6.71 & 6.60 & - & 6.34 & الآس الهيدروجيني قبل التعتيق \\
\hline 6.72 & 6.59 & - & 6.41 ج د & الآس الهيدروجيني بعد التعتيق \\
\hline 0.190. & 0.21 أب & 0.22 & 0.23 & الحموضة التسحيحية \\
\hline
\end{tabular}

التقديرات الفيزيائية

يلاحظ من الجدول (5) انخفاض في الوزن النوعي لمخاليط عينات حليب جوز الهند حيث يلاحظ حصول عينة المقارنة على قيمة معنوية والتي كانت 1.1042 في حين كانت اقل قيمة معنوية لعينة حليب جوز الهند وعند نسبة استبدال 100\% فئن ويعود 
السبب الى انخفاض كثافة دهن حليب جوز الهند واتفقت هذه النتيجة مع Al-Adwani [28] عند استخدام زيت بذور الكتان في

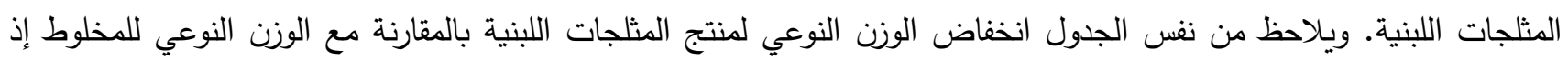
كان الوزن النوعي لعينة المقارنة (المنتج) 0.9201 بينما كان في المخلوط 1042 وكنلك الحال الحال لبقية العينات المستبدل فيها حليب الابقار بحليب جوز الهند وهذا بسب زيادة نسبة الريع في المنتوج مما أدى الى انخفاض الوزن النوعي للمنتوج بسبب الندماج الهواء والاحتفاظ به مما يقلل من الوزن النوعي للمنتج ويزيد من نسبة الريع.

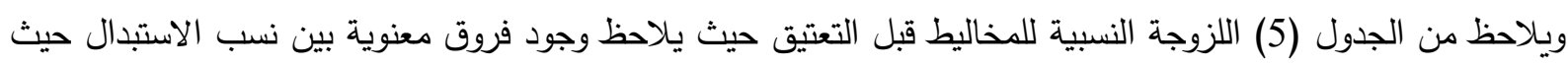

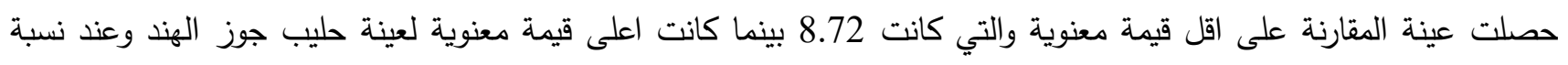
استبدال 100\% والتي كانت 13.04 ويعود ذلك لاحتواء دهن حليب جوز الهند على نسبة عالية من الاحماض الدهنية المشبعة

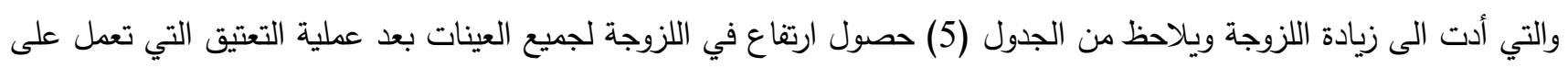
زيادة تماسك البروتين وتقليل الماء الحر في المخلوط. ويلاحظ من الجدول (5) النسبة المئوية للريع حيث يلاحظ ارتفاع نسبة الريع مع زيادة نسب الاستبدال بحليب جوز الهند حيث كانت اعلى قيمة للريع عند نسبة استبدال 100\% والتي كانت 82.19 بينما كانت لعينة المقارنة اقل قيمة للريع والتي كانت

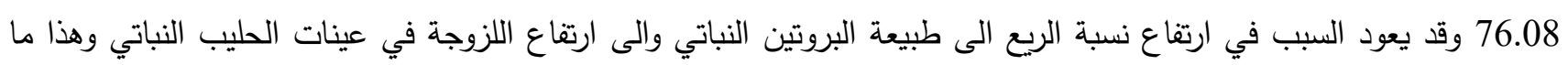
أكده Abdullah [29] اللذين أشاروا الى دور ليسيثين (lecithin) في فول الصويا كمستحلب وكعامل لرفع اللزوجة وزيادة استقرار القوام في المثلجات اللبنية وبالتالي ارتفاع نسبة الريع وتتفق هذه النتائج ايضاً مع ما وجده Ahsan [30] واللذين أشاروا الى زيادة الريع عند استبدال حليب الابقار بحليب فول الصويا في صناعة الايس كريم.

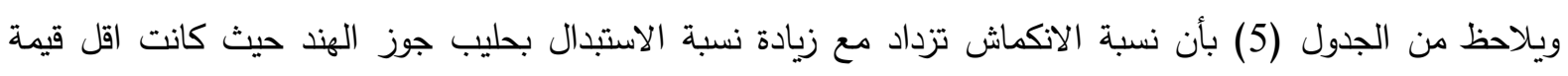

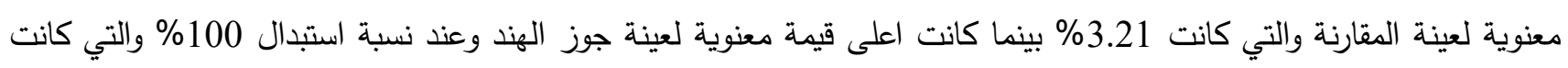
4.18\% وذكر سليم (1986) أن نسبة الانكماش تتأثر بعدة عوامل منها نسبة الريع وتركيب المخلوط وتفاوت درجة التصلب وكما يلاحظ من الجدول (5) تتاسب الريع طردياً مع الانكماش وهذا الانكماش بسبب فقدان خلايا الهواء نتيجة تحطم غشاء الـ .Lamella

ويلاحظ من الجدول (5) أن نسب الانصهار تتخفض مع زيادة نسب الاستبدال بحليب جوز الهند حيث بلغت اعلى قيمة

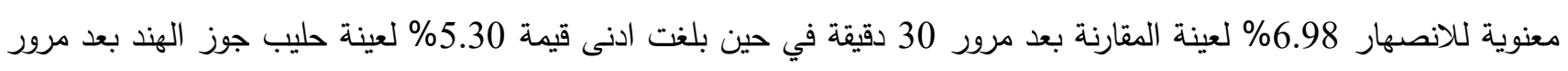

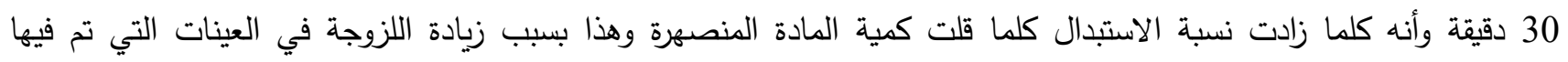
الاستبدال بسبب القابلية العالية لبروتينات الحليب النباتي (حليب جوز الهند) على امتصاص وتلقيليل نسبة الماء الحر وهذا يتفق مع ولى ما وجده Akesowan [31] الذي ذكر بأن نسبة الانصهار تتخفض مع زيادة اللزوجة.

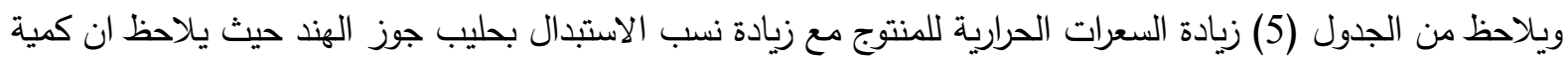

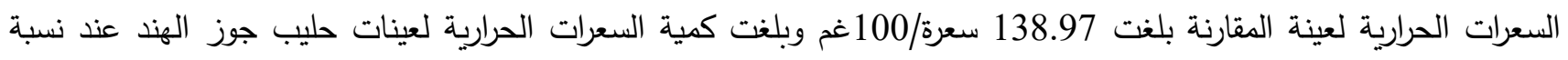
استبدال 100\% اعلى ما يمكن والتي كانت 141.60 سعرة/غم. لعندة 
جدول (5) التقديرات الفيزيائية للمثلجات اللبنية المستبدل فيها حليب الابقار بالحليب النباتي.

\begin{tabular}{|c|c|c|c|c|c|}
\hline \multicolumn{4}{|c|}{ النسبة المئوية للاستبدال } & \multirow{2}{*}{\multicolumn{2}{|c|}{ الخواص الفيزيائية }} \\
\hline$\% 100$ & $\% 70$ & $\% 35$ & عينة المقارنة & & \\
\hline 1.0591 د & 1.0602 & 1.0680 ب & 1.1042 & \multicolumn{2}{|c|}{ الوزن النوعي للمخلوط } \\
\hline 0.7291 & 0.7900 ج & 0.8521 & 0.9201 & \multicolumn{2}{|c|}{ الوزن النوعي للمنتج } \\
\hline 13.04 & 11.89 ب & 10.01 ج & 8.72 & \multicolumn{2}{|c|}{ اللزوجة النسبية قبل التعتيق } \\
\hline 14.16 & 12.94 ب & 11.12 ج & 9.90 9.90 & \multicolumn{2}{|c|}{ اللزوجة النسبية بعد التعتيق } \\
\hline 82.19 & ت & 78.04 ج & 7 76.08 د & \multicolumn{2}{|c|}{ 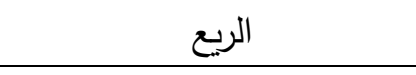 } \\
\hline 4.18 & 3.78 ب & 3.43 ج & 3.21 & \multicolumn{2}{|c|}{ الانكماش } \\
\hline ل 5.30 & 5.89 & 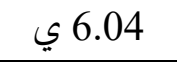 & 6.98 ط & بعد 30 دقيقة & \multirow{3}{*}{ الانصهار } \\
\hline ح 28.78 & j28.00 & 28.91 و & 29.68 هـ & بعد 60 دقيقة & \\
\hline 65.64 65.64 & 67.74 ج & 68.79 & 70.33 & بعد 90 دقيقة & \\
\hline 141.60 & 140.91 & 139.55 & 138.97 د & \multicolumn{2}{|c|}{ لسعرات الحرارية (سعره/100غم) } \\
\hline
\end{tabular}

صفات التقييم الحسي بعد التصنيع وبعد الخزن لمدة 14 يوم. يلاحظ من الجدول (6) ان جميع العينات المحتوية على حليب جوز الهند نالت درجات تقييم حسي اعلى من عينة المقارنة والتي كانت 87.30 بعد التصنيع و 82.90 بعد الخزن لمدة 14 يوم بينما كانت اعلى لدرجات التقييم الحسي لنسبة الاستبدال 100 والتي كانت 94.60 بعد التصنيع و 91.63 بعد الخزن لمدة 14 يوم. جدول (6) التقييم الحسي لمنتوج المثلجات اللبنية المستبدل فيها حليب الابقار بالحليب النباتي.

\begin{tabular}{|c|c|c|c|c|c|}
\hline \multicolumn{4}{|c|}{ النسبة المئوية للاستبدال } & \multirow{2}{*}{\multicolumn{2}{|c|}{ الصفة المقيمة }} \\
\hline$\% 100$ & $\% 70$ & $\% 35$ & عينة المقارنة & & \\
\hline 48.20 & 47.40 & 46.40 & 43.50 & الطعم 50 درجة & \multirow{5}{*}{ بعد التصنيع } \\
\hline 27.06 & 26.20 & 26.60 & 26.76 & القوام والتركيب 30 درجة & \\
\hline 9.80 & 9.06 & 9.20 & 8.40 & اللون 10 درجة & \\
\hline 9.06 & 9.06 & 8.53 & 7.60 & المظهر الخارجي 10 درجة & \\
\hline 94.60 & 91.60 & 89.80 & 87.30 & المجموع & \\
\hline 47.00 & 45.90 & 44.40 & 41.50 & الطعم 50 درجة & \multirow{5}{*}{ بعد الخزن لمدة 14} \\
\hline 26.06 & 25.20 & 25.60 & 25.76 & القوام والتركيب 30 درجة & \\
\hline 8.70 & 7.96 & 8.10 & 7.20 & اللون 10 درجة & \\
\hline 9.50 & 8.92 & 8.33 & 7.30 & المظهر الخارجي 10 درجة & \\
\hline 91.63 & 87.70 & 85.40 & 82.90 & المجموع & \\
\hline
\end{tabular}


يبين من الجدول (7) العدد الكلي للبكتريا وبكتريا القولون وبكتريا Staph.aureus لمنتج المثلجات اللبنية المستبدل فيها حليب الابقار بحليب جوز الهند وحليب اللوز بعد الخزن لمدة 14 يوم إذ يلاحظ من الجدول أن العدد الكلي للبكتريا كان منخفضاً

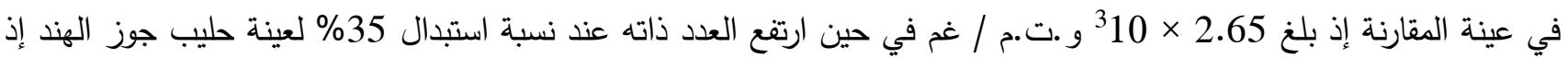

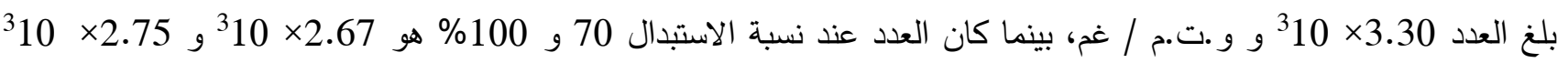
و.ت.م / غم على التوالي.

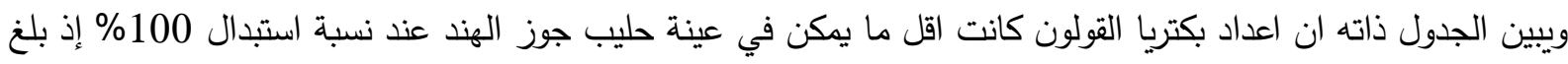

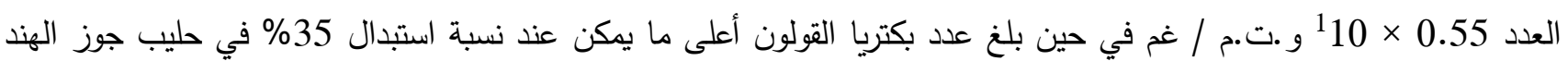

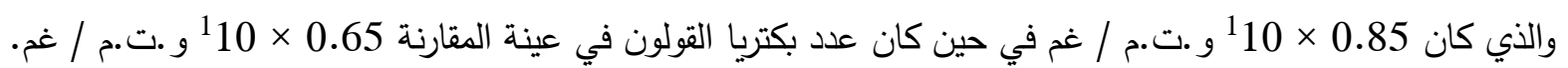
ويبين نفس الجدول اعداد بكتريا Staph.aureus أذ كانت اقل ما يمكن في عينة المقارنة إذ بلغ العدد 0.15 × 0.10

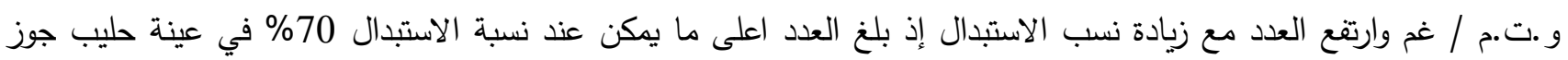

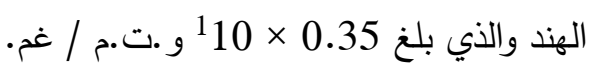
ويعود ارتفاع اعداد الاحياء المجرية الى احتواء حليب جوز الهند على نسبة اعلى من العناصر الغذائية واتفقت هذه النتائج مع ما

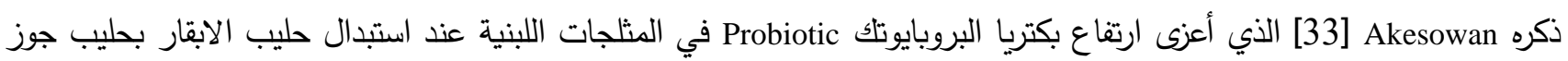

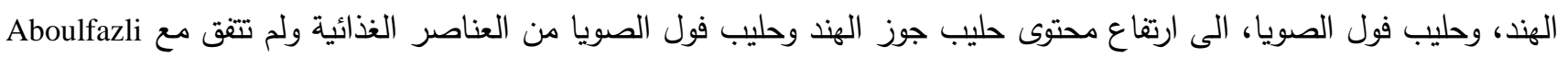
وآخرون [34] اللذين أثاروا الى عدم حصول تغيير في محتوى المثلجات اللبنية من بكتريا البروبايوتك Probiotic عند استبدال حليب الابقار بحليب جوز الهند وحليب فول الصويا. جدول (7) المحتوى الميكروبي في المثلجات اللبنية المستبل فيها حليب الابقار بحليب جوز

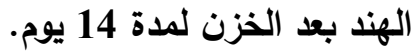

\begin{tabular}{|c|c|c|c|c|c|}
\hline \multicolumn{3}{|c|}{ النسبة المئوية للاستبدال } & \multirow{2}{*}{ عينة المقارنة } & \multirow{2}{*}{ نوع الاختبار الميكروبي } & \multirow{2}{*}{ البديل } \\
\hline 100 & 70 & 35 & & & \\
\hline 2.75 & 2.67 & 3.30 & 2.65 & العدد الكلي للبكتريا & \multirow{3}{*}{ جوز الهند } \\
\hline 0.55 & 0.75 & 0.85 & 0.65 & بكتريا القولون (×10¹) & \\
\hline 0.25 & 0.35 & 0.30 & 0.15 & $\left({ }^{1} 10 \times\right)$ Staph.aureus & \\
\hline
\end{tabular}

الاستنتاجات

1- أمكانية استخدام الحليب النباتي ( حليب جوز الهند ) في المثلجات اللبنية مع أعطاء المنتج صفات وخواص فيزيائية مقاربة لعينة المقارنة وصفات حسية أعلى من عينة المقارنة. 2- أفضل نسب الاستبدال كانت عند 100٪ بحليب جوز الهند حيث حصلت على أعلى درجات التقييم الحسي.

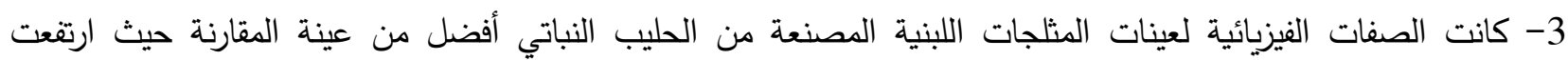
اللزوجة وكذللك النسبة المئوية للريع وازدادت مقاومة الانصهار مع زيادة نسب الاستبدال. 4 ازدادت السعرات الحرارية مع زيادة نسب الاستبدال بحليب جوز الهند. 


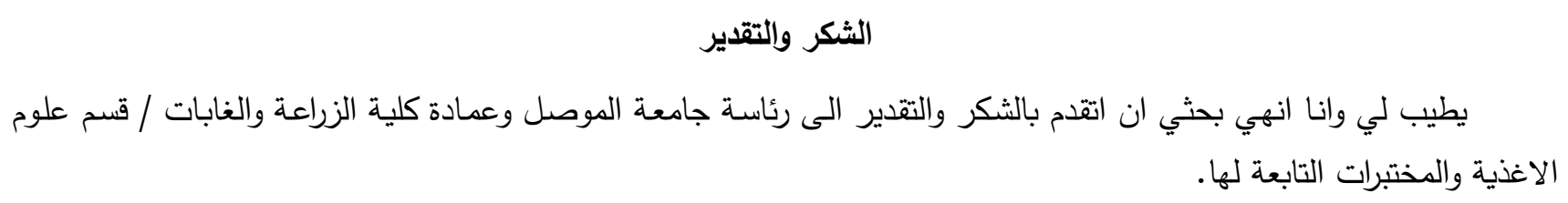

\section{References المصادر}

[1] Salim, R. M. " ice cream". House of Books for Printing and Publishing. University of Al Mosul. (1986). (In Arabic).

[2] Prado F., Parada J., Pandey A. and Soccol C. Food Res Int (2008).41:111-123.

[3] Swati S., Tyagi S. and Rahul K. J Food Sci Technol. (2016).

[4] Outi E., Viivi W., Emanuele Z. and Elke K. Crit. Rev. Food. Sci. Nutr. In press. (2015).

[5] Rustom I., Lopez-Leiva M. and Nair B. Int. J. Food Sci. Technol. (1995). 30: 773-781.

[6] Kim H., Bang J., Kim Y., Beuchat L., and Ryu J. Lett. Appl. Microbiol. (2012). 55:218-223.

[7] Kate P. E., Rao K.J., Deshmukh G. P., Datir R.P and Tambade P.B. 6(9): (2017). 6073-6078.

[8] Min, D.B. and Ellefson, W.C. "Fat Analysis. In: Food Analysis". Nielsen, S.S. $4^{\text {th }}$.ed. Springer Science \& Business Media. (Chapter 8). pp 118-132. (2010).

[9] Hool, R. Barbano, D. M. Bradley, R. Bulthaus, M. Lynch, J. and Reddy, R. "Chemical and physical Methods. In: Standard Methods for the Examination of Dairy products Wehr, H.M. and Frank", J.F. (Ed). 17th ed. Washington, American Public Health Association. (Chapter 15). Pp: 363-532. human health. J. Nutr:3025(suppl):384S-390S. (2004).

[10] Bradley, R. L. "Moisture and Total Solids Analysis. In: Food Analysis Nielsen", S.S. (Ed). Fourth Edition. Springer Science \& Business Media. (Chapter 6), (2010).

[11] Pearson, D. "The chemical analysis of foods". 7th ed. Churchill Iivingstone. Edinburgh. London and New York.P. (1996).

[12] Marshall, M.R. "Ash Analysis. In: Food Analysis Nielsen", S.S. (Ed). Fourth Edition. Springer Science \& Business Media. (Chapter 7). (2010)..

[13] Ling, E.R. "A text book of dairy chemistry". Vol. 2, practical, $3^{\text {rd }}$. ed.Chapman and Hall Limited, London. (1963).

[14] Arbuckle, W.S. "Ice cream". $4^{\text {th }}$.ed. The AVI Publishing Co. Inc. Westport. Conn. (1986).

[15] Al-Waeli, M. S.M. Master Thesis, College of Agriculture and Forestry, University of Mosul. (1988). (In Arabic).

[16] Buck, J.S.Walker. C.E. and Picrce .M.M., J. Food Sci. (1986). 51 : 2.

[17] Al-Zuhairi, A.M.T. "Human nutrition". House of Books for Printing and Publishing, University of Mosul. (2000). (In Arabic).

[18] Frank, K. F. and Yousef, A. E. "Tests for groups of microorganisms, In: Standard Mcthods for the Examination of Dairy Products". Wehr, H. M. and Frank, J. F. (Ed). 17th edition. Washington, Americcan public Health Association. (Chapter 15). (2004).

[19] Chen, Yi. Wu, H. and Yanagida, F. Brazilian J. Microbiol. (2010). 41: 916-921.

[20] American Public Healh Association Standard Methods for the examination of dairy products . 14th . ed Washington . (1987).

[21] Al-Rawi, K.M. and Abdulaziz M.K. "Design and Analysis of Agricultural Experiments", Mosul University Press. (1980) (In Arabic).

[22] Belewu, M.A., Abdulsalam, K.O., Belewu, K. and Belewu, N. Asian J. Agri. Rural Dev. (2013).

[23] Balogun, M.A., Kolawole, F.L., Joseph, J.K., Adebisi, T.T., Ogunleye, O.T. University of Ilorin, Department of Home Economics \& Food Science, Ilorin, Nigeria. (2016).

[24] Akoma, M. C.; M. Mnist; M. Elekwa; A. Hnd and O. Hnd. Yogurt from Coconut and Tigernuts. Department of Science Laboratory Technology. The Federal polytechnic, Niger State, Nigeria. (2000).Vol. 5, No. 4. 
[25] Okorie. S.U. and Adedokun. I.I. Department of Food Science and Technology, Imo State University, Owerri, Imo State, Nigeria. (2013).

[26] Ekanem, George Okon and Philippa C. Ojimelukwe. J. Adv. Microbiol. (2017).

[27] Abdel-Rahman , H.A. Egy. J.Dairy Sci. (2003).31:41-419.

[28] Al-Adwani, Y and Abdul Sattar M.A. Master Thesis, Department of Food Science, College of Agriculture and Forestry, University of Mosul. (2013). (In Arabic).

[29] Abdullah, M., Rehman, S., Zubair, H., Saeed, H., Kousar, S., and Shahid, M. Pak. J. Nutr., (2003). 2, 305-311.

[30] Ahsan, S.; T. Zahoora; M. Hussainb; N. Khalida; A. Khaliqa and M. Umar Preparation and quality characterization of soy milk based non-dairy ice cream. International Journal of Food and Allied Sciences, (2015).Volume 01, Issue 01.

[31] Akesowan, A. Thai. J. Agric. Sci., (2009). 42, 1-6.

[32] Central Organization for Standardization and Quality Control (1981). Amendment of Standard Specifications No. 703: Food Ice Cream, Planning Council, Baghdad-Republic of Iraq.

[33] Akesowan, A. (2009). Influence of soy protein isolate on physical and sensory 416 properties of ice cream. Thai Journal of Agricultural Science, 42: 1-6.

[34] Aboulfazli, F.; A. Bakr and S. Ahmad (2016). Effects of the replacement of cow milk with vegetable milk on the count of probiotics and changes in sugar and amino acid contents in fermented ice creams. LWT - Food Science and Technology. 